\title{
IDIOPATHIC HYDRONEPHROSIS IN THE YOUNG MILITARY POPULATION
}

\author{
MAJ N E CETTI, MA, FRCS, RAMC \\ Queen Elizabeth Military Hospital, Woolwich
}

SUMMARY: Fifty cases of idiopathic hydronephrosis seen by the Army Urology Unit from 1972 to 1977 are reported. Special points of interest are the low average age and the high incidence of alcohol-induced pain and sport-induced haematuria. The diuretic renogram has proved to be particularly useful in the follow-up of these cases. Conservative surgery is re-affirmed as the ideal treatment.

\section{Introduction}

Idiopathic, congenital or primary pelvic hydronephrosis is a well recognised condition, which can present at any age $^{1}$, but most commonly in children ${ }^{2}$ and in the third decade. The aetiology is still uncertain, though the work of Murnagham ${ }^{3}$ and Whitaker ${ }^{4}$ has demonstrated that there is an abnormality of muscular peristaltic conduction in the pelvis and pelviureteric junction, which constitutes a functional obstruction to urine flow. Many series have described the diagnosis, surgery and follow-up of this condition $^{1}{ }^{2}{ }^{5-10}$, but none have concentrated on the young adult. In Hanley's ${ }^{6}$ paper he noted that over half of his cases were Army personnel and that their average age at operation was eight years younger than that of his civilian patients. This report covers the experience of the Army Urology Unit with idiopathic hydronephrosis in the six years 1972 to 1977 .

\section{Materials and methods}

The records of all cases of idiopathic hydronephrosis presenting in the years 1972 to 1977 were studied. Many were still under review, but up-to-date information on those not seen in the last six months was obtained from the patients themselves and their medical attendants. The following were noted:

Age, sex, presenting symptoms, time taken to diagnose from first onset of symptoms, intravenous urogram and diuretic renogram findings, operative findings and follow-up results to mid-1979.

\section{Results}

The number in the study with full follow-up was 50 patients. Their average age was 23.5 years and the male to female ratio four to one (contrast the civilian series' average age of 36.5 years and male to female ratio of two to three). The presenting symptoms are shown in Table $\mathrm{I}$. The times taken for the true diagnosis to be established after the onset of the first relevant symptoms were:-

i. A few days; 10 per cent. ii. One to six months; 20 per cent. iii. One year; 14 per cent. iv. Several years; 56 per cent.

It can be seen that over 50 per cent of patients had referrable symptoms well before joining the Service. Several patients were investigated, and a few operated upon, for other diagnoses (Table II). In the routine assessment of cases, intravenous 
urography and isotope renography, before and after intravenous frusemide, were employed. These tests agreed in pelvic-ureteric junction (PUJ) obstruction in 90 per cent of cases. Three 'normal' kidneys on intravenous urogram (IVU) were shown renographically, and proven surgically, to be obstructed. Bilateral hydronephrosis was noted in 10 patients, one side always being the worse. The findings noted at operation are listed in Table III. The 60 per cent incidence of lower polar vessels (LPV) accords with other series ${ }^{6}{ }^{3}$.

In 85 per cent of the cases some type of pyeloplasty was performed and nepherectomy in the other 15 per cent, when the kidney was thought to be unsalvageable. The Anderson-Hynes disconnection pyeloplasty was used in all but five cases (two Culp and three Foley Y-V). Re-exploration was required in six patients, when there was recurrent or persistent obstruction confirmed by renogram, three having a 'redo' pyeloplasty and three a secondary nephrectomy. The followup results are given in Table IV.

Table 1

Presenting symptoms

\begin{tabular}{lcc}
\hline \multicolumn{1}{c}{ Symptoms } & $\begin{array}{c}\text { This series } \\
\text { (percentage) }\end{array}$ & $\begin{array}{c}\text { Civilian series } \\
\text { (percentage) }\end{array}$ \\
\hline Loin pain alone & 45.5 & 55.5 \\
Loin pain after drinking & 23.7 & 7.4 \\
Loin pain with haematuria & 10.9 & 16.6 \\
Haematuria alone & 1.8 & 3.7 \\
Haematuria from sport (trauma or exertion) & 12.7 & 1.8 \\
Urinary tract infection & 5.4 & 12.9 \\
(Considered to be 'hysterical' or 'over-reacting' on first presentation & 5.0 & - ) \\
\hline
\end{tabular}

Table II

Other diagnoses

\begin{tabular}{lc|lcc}
\hline Diagnosis & Number & & Diagnosis & Number \\
\cline { 1 - 1 } \cline { 5 - 6 } Appendicitis - appendicectomy & 2 & & Large bowel pain - sigmoidscopy & 1 \\
Cholecystitis - Cholecystectomy & 1 & & Abdominal pain - cholecystogram, \\
Tubo-ovarian pain-laparoscopy & 1 & & barium meal, endoscopy & 1 \\
Ureteric stone & 2 & & Trauma & 5 \\
\hline
\end{tabular}

Table III

Operative findings

\begin{tabular}{cc|lcc}
\hline Findings & Number & & \multicolumn{1}{c}{ Findings } & Number \\
\cline { 1 - 2 } Lower Polar vessel (LPV) & 20 & & Narrow PUJ alone & 8 \\
LPV plus adhesions and/or kinking & 7 & & Atonic PUJ alone & 7 \\
LPV plus 'narrowed' PUJ & 4 & & 'High take-off' ureter & 1 \\
LPV plus 'atonic' PUJ & 3 & & \\
\hline
\end{tabular}


Table IV

Follow-up results

\begin{tabular}{|c|c|c|}
\hline Follow-up results & Number & Remarks \\
\hline Still serving fully fit & 21 & \\
\hline Still serving downgraded & 2 & \\
\hline Discharged from Service for Kidney problems & 5 & Now fit -4 , Renal trouble-1 \\
\hline Lelt Army (run-out. buy-out etc) - Fully fit & 11 & \\
\hline - Renal trouble & 3 & \\
\hline CIVILIANS (families) - Fully fit & 7 & \\
\hline - Renal trouble & 1 & \\
\hline Total fit in 1979 & 43 & Out of $50-86$ per cent. \\
\hline
\end{tabular}

\section{Discussion}

It is interesting that in this group of young service people the presentations of alcoholic-induced pain and sport-induced haematuria are much more common than in civilian series. Many young soldiers are initiated into drinking habits and they are subject to rigorous physical exercise. The fact that over half of these patients had symptoms for several years before final diagnosis is a common finding ${ }^{1}$. The symptoms are often vague, mild and intermittent. However close questioning and informed suspicion should have led to earlier investigation in many of the cases.

Since 1968 we have been using the diuretic renogram as routine investigation along with the intravenous urogram to assess patients with idiopathic hydronephrosis. Our technique has been the same as that described more recently ${ }^{11} 1213$. The diuretic renogram confirms obstruction in the majority of cases with positive urograms (Fig, 1). However it also identifies those dilated systems which are
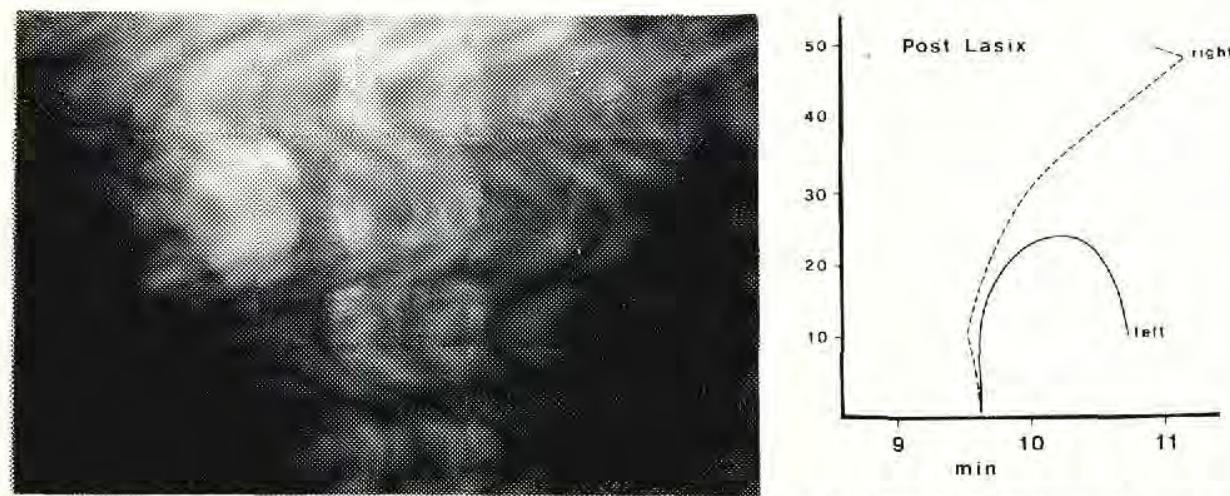

Fig 1. Unequivocal pelviureteric junction obstruction shown in (left) the intravenous urogram and (right) the diuretic renogram

capacious or atonic, but not obstructed (Fig. 2), and also normal-appearing systems which are the seat of intermittent obstruction (Fig. 3). This test is even 

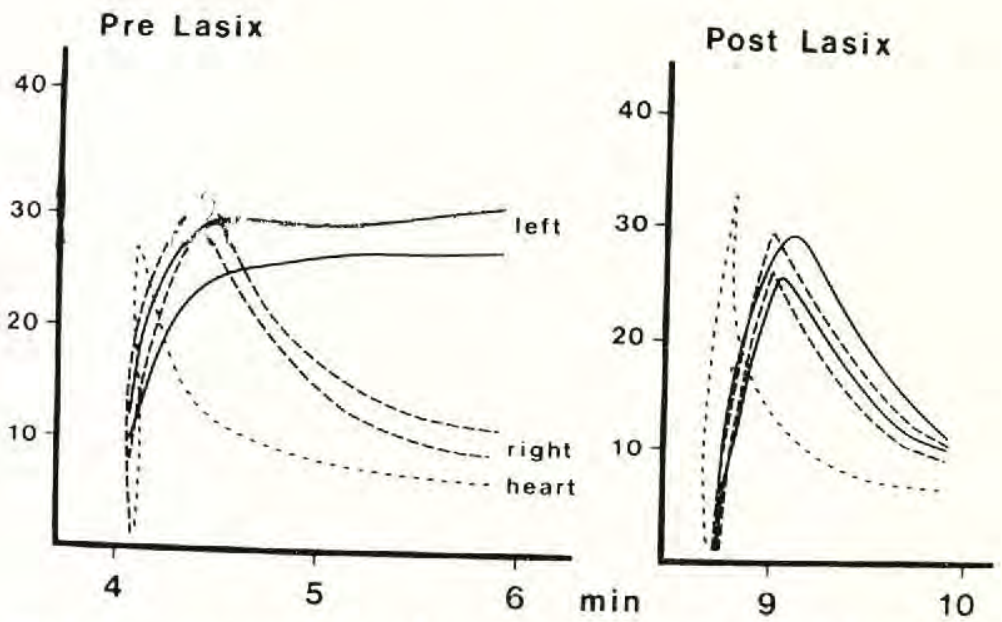

Fig 2. Dilated system post-pyeloplasty shows 'obstructed' picture pre-lasix (left), but normal drainage post-lasix (right), ie capacious system only
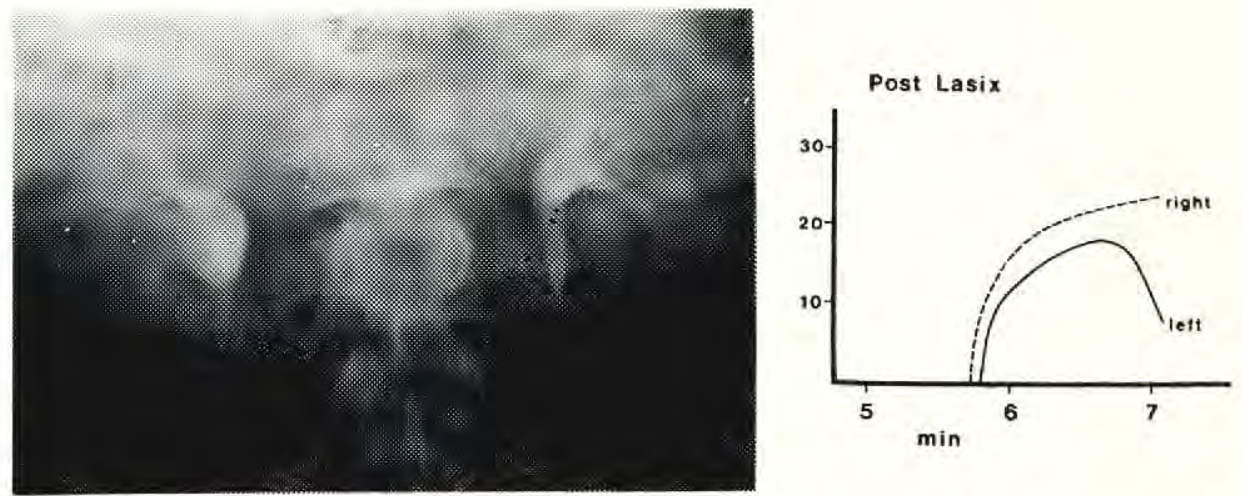

Fig 3. Case of intermittent obstruction with (left) normal intravenous urogram, but (right) obstructed diuretic renogram

more helpful in the follow-up period. It is simple and rapid with minimal radiation and will solve the not uncommon postoperative problems of the patient with recurrent pain or the system which remains dilated on urography. In fact, postpyeloplasty follow-up with diuretic renogram alone would now seem logical.

Idiopathic hydronephrosis is potentially bilateral and obstruction in the remaining kidney after nephrectomy has been recorded, often several years later $^{1} 8$ in 14 . One of our cases required pyeloplasty in such a remaining kidney 17 years after nephrectomy. It is now suggested that patients having nephrectomy for idiopathic hydronephrosis should be followed indefinitely with diuretic renography to detect early obstruction in the remaining kidney.

Our operative findings, preference for the disconnection pyeloplasty and re-exploration rate are no different from other reports. This study confirms that pyelopasty carries long-term success ${ }^{9}$. 


\section{Conclusions}

The Services require full physical fitness from all its members. The morbidity associated with idiopathic hydronephrosis could be minimised by earlier recognition:

i. More detailed enquiry at the entry medical may uncover positive or suspicious histories, leading to urological investigation at this stage.

ii. Patients with loin pain after drinking or haematuria, after exertion or trauma (however minor) at sport should be investigated.

iii. A young patient with intermittent unexplained abdominal pain should have an intravenous urogram and diuretic renogram.

Conservative surgery is the ideal, allowing the serviceman to return to full fitness within six to 12 months. Follow-up of the patient with idiopathic hydronephrosis after pyeloplasty or nephrectomy can be achieved with diuretic renography alone.

\section{Acknowledgements}

I wish to thank Col I S Lister, FRCS, L/RAMC for allowing me to study these cases under his care, and the Illustration Department of the Nurses Training School, Queen Elizabeth Military Hospital, Woolwich, for the figures.

\section{REFERENCES}

1. RoBerts, J B M and SLADE, N (1964). The natural history of primary pelvic hydronephrosis. Br J Surg 51, 759-762.

2. NixON, H H (1953). Hydronephrosis in children. Br J Surg 40, 601-609.

3. MURNAGHAM, G F (1958). The mechanism of congenital hydronephrosis with reference to the factors influencing surgical treatment. Ann $R$ Coll Surg 23, 25-46.

4. Whitaker, R H (1975). Some observations and theories on the wide ureter and hydronephrosis. Br J Urol 47, 377-385.

5. BuRNS, C N, Drew J E and DeAN, A L (1953). Ureteropelvic obstruction with hydronephrosis: Treatment by pyeloplasty in 23 cases. $J$ Urol 70, 846-856.

6. HANLEY, H G (1959). The pelvic-ureteric junction: a cine-pyelography study. $\mathrm{Br} J$ Urol 31, 377-384.

7. SuTHERLAND, H (1963). A review of experience with the Anderson-Hynes plastic operation for hydronephrosis. Br J U rol 35, 1-10.

8. Williams, D I and Karalaftis, C M (1966). Hydronephrosis due to pelvic-ureteric obstruction in the new-born. Br J Urol 38, 138-144.

9. Notley, R G and Beaugie, J M (1973). The long-term follow-up of Anderson-Hynes pyeloplasty for hyronephrosis. $B r J$ Urol 45, 464-467.

10. HANNA, M K (1978). Some observations on congential ureteropelvic junction obstruction. Urology 12, 151-159.

11. O'REILLY, P H, et al (1978). Diuresis renography in equivocal urinary tract obstruction. Br J Urol 50, 76-80.

12. O'Reilly, P H Lawson, R S Shields, R A and Testa, H (1979). Idiopathic hydronephrosis: the diuresis renogram: a new non-invasive method of assessing equivocal pelvioureteral junction obstruction. J Urol 121, 153-155.

13. LuPTON, E W et al (1979). Diuresis renography and morphology in upper urinary tract obstruction. Br J Urol 51, 10-14.

14. Michigan, S Whelton, P K and Walsh, P C (1978). Forgotten kidney: asynchronous bilateral ureteropelvic junction obstruction. Urology 12, 565-566. 